\title{
Creation-field theory from dimensional analysis
}

Lord E A 1974 Pramāṇa 3 (No. 1) 35

In equation (2.8) of this work, a factor $\sigma$ should occur on the right hand side, and in equation (2.9) there should be a factor $\sigma^{-1}$. Consequently, the factors $e^{C}$ in (5.8) and subsequent equations should be absent. Because of this error, the conclusions of section 6 are wrong. The cosmological implications of the conformally-invariant two-scalar theory are still under investigation.

\section{Optical colours and polarization of a model reflection nebula.}

Shah G A 1974 Pramāṇa, 3 (No. 5) 338-353.

Equation 21: The minus sign in the denominator is to be changed to plus. 